INTERVENTIONAL CARDIOLOGY AND SURGERY

\title{
Renal function and long term mortality after unstable angina/non-ST segment elevation myocardial infarction treated very early and predominantly with percutaneous coronary intervention
}

\author{
C Mueller, F-J Neumann, A P Perruchoud, H J Buettner
}

Heart 2004;90:902-907. doi: 10.1136/hrt.2003.021741

See end of article for authors' affiliations

Correspondence to: Dr Christian Mueller, Department of Internal Medicine, University Hospital, Petersgraben 4 $\mathrm{CH}-4031$ Basel,

Switzerland:

chmueller@úhbs.ch

Accepted

12 November 2003
Objectives: To quantify the impact of baseline renal function on in-hospital and long term mortality in patients with unstable angina/non-ST elevation acute myocardial infarction (UA/NSTEMI) treated with a very early invasive strategy.

Design: Prospective cohort study of 1400 consecutive patients with UA/NSTEMI undergoing coronary angiography and subsequent coronary stenting of the culprit lesion as the primary revascularisation strategy within 24 hours of admission. Patients were stratified according to calculated glomerular filtration rate (GFR) on admission.

Results: In-hospital mortality was $0 \%$ among patients with a GFR $\geqslant 130 \mathrm{ml} / \mathrm{min} / 1.73 \mathrm{~m}^{2}, 0.4 \%$ with a GFR of $90-129 \mathrm{ml} / \mathrm{min} / 1.73 \mathrm{~m}^{2}, 2.6 \%$ with a GFR of $60-89 \mathrm{ml} / \mathrm{min} / 1.73 \mathrm{~m}^{2}$, and $5.1 \%$ with a GFR of $<60 \mathrm{ml} / \mathrm{min} / 1.73 \mathrm{~m}^{2}$. Cumulative three year survival rates were $92.6 \%, 95.5 \%, 91.9 \%$, and $76.8 \%$, respectively. Patients with a GFR of $<60 \mathrm{ml} / \mathrm{min} / 1.73 \mathrm{~m}^{2}$ were four times more likely to die in hospital (hazard ratio (HR) 4.0, 95\% confidence interval (CI) 1.8 to $9.1 ; p=0.001$ ) and four times more likely to die during long term follow up (HR 4.0,95\% Cl 2.5 to 6.4; $\mathrm{p}<0.001)$. After adjusting for potential confounders, a GFR of $<60 \mathrm{ml} / \mathrm{min} / 1.73 \mathrm{~m}^{2}$ remained a strong independent predictor of long term mortality (HR 2.6, 95\% Cl 1.5 to $4.5 ; \mathrm{p}=0.001$ ).

Conclusions: Baseline renal function is a strong independent predictor of in-hospital and long term mortality after UA/NSTEMI treated with very early revascularisation.
A bout four million patients attend emergency departments in Europe each year with chest pain and suspected unstable angina/non-ST segment elevation myocardial infarction (UA/NSTEMI). ${ }^{1}$ However, risk stratification is often particularly challenging in UA/NSTEMI. Early coronary angiography and revascularisation has been proposed as a novel potentially superior management strategy for these patients. ${ }^{2-5}$ Current practice guidelines for the management of patients with UA/NSTEMI recommend an early invasive strategy for most patients. ${ }^{2}{ }^{6}$ Predictors of long term mortality in UA/NSTEMI treated with an early invasive strategy remain to be established.

The implications of chronic kidney disease for cardiovascular outcomes have attained increasing recognition. ${ }^{78}$ Large registries including predominantly patients with ST elevation myocardial infarction treated with thrombolytic agents suggested that baseline renal function measured as serum creatinine or estimated creatinine clearance is a predictor of mortality. ${ }^{9-11}$ McCullough and colleagues ${ }^{12}$ confirmed this observation among patients admitted to a single coronary care unit. In these studies, patients were primarily treated conservatively with anti-ischaemic and antithrombotic medication unless ST elevation was evident on the admission ECG. Coronary angiography was performed only after "cooling down" with medical treatment and was restricted to patients with recurrent ischaemia.

Thus, the present study had two aims: firstly, to explore the association between baseline renal function and mortality after UA/NSTEMI in a large cohort of consecutive unselected patients treated uniformly very early and predominantly with percutaneous coronary intervention (PCI); and secondly, to test whether this latest, aggressive treatment is both safe and efficacious for patients presenting with renal dysfunction.

\section{METHODS}

\section{Patient population}

From January 1996 to December 1999, consecutive patients admitted to our centre with UA/NSTEMI were treated with a very early invasive strategy. Patients undergoing coronary angiography for symptoms of myocardial ischaemia occurring at rest (Braunwald class IIIB unstable angina) were eligible for inclusion in this study. ${ }^{13}$ We excluded patients with de novo angina pectoris on exertion or worsening angina during exertion only (Braunwald class $\mathrm{lA}-\mathrm{C}$ ), patients with persistent ST elevation, and patients with postinfarction angina (Braunwald class 1C, 2C, or 3C), patients in whom angiography was not performed because of patient refusal $(n=6)$ or extremely severe concomitant disease ( $n=9$ with severe dementia or advanced malignancy), and patients with no serum creatinine determined on admission $(n=50)$. Therefore, this study included $96 \%$ (1400 of 1465) of the total number of consecutive patients with UA/NSTEMI admitted to our centre and $99 \%$ of those with serum creatinine available. These include patients with end stage renal disease on dialysis, high bleeding risks, and

\footnotetext{
Abbreviations: $\mathrm{BARI}$, bypass angioplasty revascularisation investigation; $C A B G$, coronary artery bypass grafting; $\mathrm{Cl}$, confidence interval; $\mathrm{CK}$, creatine kinase; GFR, glomerular filtration rate; $\mathrm{PCl}$, percutaneous coronary intervention; TACTICS-TIMI 18, treat angina with Aggrastat and determine cost of therapy with an invasive or conservative strategy-thrombolysis in myocardial infarction 18; UA/NSTEMI, unstable angina/non-ST segment elevation myocardial infarction
} 
prior stroke. The study was carried out according to the principles of the Declaration of Helsinki and was approved by the institutional review board. Informed consent was obtained from all participating patients. At hospital discharge all patients were prescribed a low cholesterol diet and statins were recommended to achieve a low density lipoprotein cholesterol concentration below $3.0 \mathrm{mmol} / \mathrm{l}$ during follow up. Angiotensin converting enzyme inhibitors were given to all patients with renal dysfunction, diabetes, or prior myocardial infarction unless they were considered hypovolaemic.

\section{Renal function and glomerular filtration rate}

The glomerular filtration rate (GFR) is the best measure of overall kidney function. ${ }^{14-16}$ We calculated GFR with the use of the abbreviated modification of diet in renal disease study equation $^{14-16}$ : GFR (in $\mathrm{ml} / \mathrm{min} / 1.73 \mathrm{~m}^{2}$ of body surface area $)=186 \times(\text { serum creatinine in } \mathrm{mg} / \mathrm{dl})^{-1.154} \times($ age in years $)^{-0.203} \times 0.742$ for female patients and $\times 1.210$ for black patients. This equation is based on data from Levey and colleagues ${ }^{15}$ on 1628 patients with 558 in the validation set.

A venous blood specimen for serum creatinine determination was drawn on admission. All samples were analysed in a central laboratory with the use of an enzymatic kit (CREA plus, Boehringer Mannheim Systems, Mannheim, Germany). Patients were divided into groups according to their renal function as assessed by GFR (National Kidney Foundation kidney disease outcomes quality initiative stages). ${ }^{14-16}$

\section{Very early revascularisation}

Patients with persistent chest pain underwent immediate coronary angiography. Among patients asymptomatic while taking medical treatment, coronary angiography was performed within 24 hours of admission. Whenever possible, coronary stenting of the culprit lesion was done immediately after angiography. Stenting was not restricted to patients with one and two vessel disease but was also favoured for patients with three vessel disease with suitable lesions. The median time interval from admission to PCI was five hours. If revascularisation was indicated but PCI was not considered the optimal treatment option (unprotected left main disease, diffuse three vessel disease), patients were scheduled for urgent coronary artery bypass grafting (CABG).

\section{Follow up}

All patients were scheduled for outpatient visits at six months. In addition, patients were contacted by questionnaire in September 2000, nearly five years after enrolment of the first patient. For patients reporting cardiac symptoms, at least one clinical and ECG examination was performed in the outpatient clinic or by the referring physician. All information derived from contingent hospital readmission records or provided by the referring physician or by the outpatient clinic was reviewed and entered on to the computer database.

\section{End points and statistical analysis}

The pre-specified primary end point was defined as death from all causes occurring in hospital or during follow up. As secondary end points we assessed non-fatal myocardial infarction and the composite of death and non-fatal myocardial infarction. Myocardial infarction was defined as typical chest pain at rest followed by an increase in creatine kinase concentration ( $\mathrm{CK}$ and $\mathrm{CK}-\mathrm{MB}$ beyond twice the upper limit of normal and five times the upper limit of normal after CABG) or new Q waves on the ECG. To meet this end point criterion, patients who had initially presented with myocardial infarction had to have new ST segment changes and an increase in CK of at least $50 \%$ over the previous trough concentration in at least two samples reaching at least three times the upper limit of normal. ECGs were recorded for all patients directly after PCI or CABG and in the following morning. In addition, cardiac markers (CK and CK-MB) were determined 8-24 hours after the intervention and additionally whenever ischaemic symptoms developed.

The statistical analyses were done with the SPSS/PC (version 11.0, SPSS Inc, Chicago, Illinois, USA) software package. Discrete variables were expressed as percentage (95\% confidence interval (CI)) and continuous variables as mean (95\% CI). A significance level of 0.05 was used. Comparisons were made by analysis of variance for independent samples and $\chi^{2}$ tests as appropriate. All hypothesis testing was two tailed. Cox proportional hazards regression analysis was used as the appropriate multivariate method for adjustment throughout. Multivariate Cox regression analysis was performed to identify independent predictors of death. All baseline clinical, laboratory, and angiographic variables were entered into the model. The cumulative survival curves were constructed with the use of the Kaplan-Meier method.

\section{RESULTS}

\section{Baseline characteristics}

GFR was estimated for 1400 consecutive patients. The median GFR was $88 \mathrm{ml} / \mathrm{min} / 1.73 \mathrm{~m}^{2}$ of body surface area (mean $89 \mathrm{ml} / \mathrm{min} / 1.73 \mathrm{~m}^{2}$ ). Table 1 describes the baseline, demographic, clinical, angiographic, and procedural characteristics of the cohort, divided into groups according to their renal function as assessed by GFR (National Kidney Foundation kidney disease outcomes quality initiative stages). ${ }^{14-16}$

Table 1 shows the differences in baseline characteristics between these groups. Patients with a GFR $<60 \mathrm{ml} / \mathrm{min} /$ $1.73 \mathrm{~m}^{2}$ of body surface area (kidney disease outcomes quality initiative stage 3-5) were older, more often had prior myocardial infarction, diabetes, and hypertension, and less often were smokers. In addition, these patients more often required mechanical cardiopulmonary resuscitation or defibrillation before admission and more often had new ST segment depression, increased troponin $\mathrm{T}$, and increased white blood cell count on admission than did patients in the other GFR ranges. Coronary angiography was performed in all 1400 patients and showed that the extent of coronary artery disease was significantly more advanced in patients with a GFR $<60 \mathrm{ml} / \mathrm{min} / 1.73 \mathrm{~m}^{2}$ of body surface area.

\section{Revascularisation}

PCI was the predominant revascularisation procedure applied in all ranges of GFR. About $70 \%$ of patients actually underwent revascularisation. The overall PCI to CABG ratio was $4: 1$, with the highest CABG rate among patients with a GFR $<60 \mathrm{ml} / \mathrm{min} / 1.73 \mathrm{~m}^{2}$ of body surface area.

\section{Outcome}

Eighty two deaths and 59 non-fatal myocardial infarctions occurred during a mean follow up of 20 months (95\% CI 19 to 21 months). The mean interval until last patient contact or patient death was 21 months in the groups with GFR $\geqslant 130 \mathrm{ml} / \mathrm{min} / 1.73 \mathrm{~m}^{2}$ (2177 person-months) and GFR 90$129 \mathrm{ml} / \mathrm{min} / 1.73 \mathrm{~m}^{2}$ (11293 person-months), 20 months with GFR $60-89 \mathrm{ml} / \mathrm{min} / 1.73 \mathrm{~m}^{2}$ (11443 person-months), and 16 months with GFR $<60 \mathrm{ml} / \mathrm{min} / 1.73 \mathrm{~m}^{2} \quad(2886$ person-months). The majority of deaths were from cardiac causes. In-hospital mortality was significantly higher among patients with a GFR $<60 \mathrm{ml} / \mathrm{min} / 1.73 \mathrm{~m}^{2}$ of body surface area than among patients with higher GFR (table 2 ). The rate was $0 \%$ with GFR $\geqslant 130 \mathrm{ml} / \mathrm{min} / 1.73 \mathrm{~m}^{2}, 0.4 \%$ with GFR 90 $129 \mathrm{ml} / \mathrm{min} / 1.73 \mathrm{~m}^{2}, 2.6 \%$ with GFR $60-89 \mathrm{ml} / \mathrm{min} / 1.73 \mathrm{~m}^{2}$, 
Table 1 Baseline patient and procedural characteristics according to glomerular filtration rate (GFR) on admission

\begin{tabular}{|c|c|c|c|c|c|c|}
\hline & \multirow{2}{*}{$\begin{array}{l}\text { All patients } \\
(n=1400)\end{array}$} & \multicolumn{4}{|c|}{ Group by GFR $\left(\mathrm{ml} / \mathrm{min} / 1.73 \mathrm{~m}^{2}\right)$} & \multirow[b]{2}{*}{ p Value* } \\
\hline & & $\geqslant 130(n=106)$ & $90-129(n=548)$ & $60-89(n=570)$ & $<60(n=176)$ & \\
\hline GFR $\left(\mathrm{ml} / \mathrm{min} / 1.73 \mathrm{~m}^{2}\right)$ & $89(27)$ & $146(15)$ & $105(10)$ & 77 (8) & $46(13)$ & \\
\hline Age (years) & 65 (11) & $58(11)$ & $61(11)$ & 67 (9) & $71(8)$ & $<0.001$ \\
\hline Female sex (\%) & 29 (27 to 32$)$ & $22(14$ to 30$)$ & 28 (25 to 32$)$ & 29 (25 to 33$)$ & 35 (28 to 42$)$ & 0.135 \\
\hline Prior MI (\%) & 33 (31 to 36$)$ & $22(14$ to 30$)$ & 28 (25 to 32$)$ & 36 (32 to 40$)$ & 45 (38 to 53$)$ & $<0.001$ \\
\hline Prior coronary bypass grafting (\%) & $14(12$ to 16$)$ & $13(7$ to 20$)$ & $12(9$ to 14$)$ & $15(12$ to 18$)$ & $15(10$ to 21$)$ & 0.291 \\
\hline Prior coronary angioplasty (\%) & $22(20$ to 24$)$ & 17 (10 to 24$)$ & $22(19$ to 26$)$ & $24(20$ to 27$)$ & 21 (15 to 27$)$ & 0.471 \\
\hline Diabetes (\%) & $19(17$ to 21$)$ & 17 (10 to 24$)$ & $16(13$ to 20$)$ & 18 (15 to 22$)$ & 30 (23 to 36$)$ & 0.001 \\
\hline Hypercholesterolaemia (\%) & 66 (63 to 68$)$ & 64 (55 to 73$)$ & $65(61$ to 69$)$ & 68 (64 to 72$)$ & $63(55$ to 70$)$ & 0.476 \\
\hline Hypertension (\%) & $62(60$ to 65$)$ & 55 (45 to 64$)$ & $56(52$ to 60$)$ & $67(63$ to 70$)$ & $71(64$ to 78$)$ & $<0.001$ \\
\hline Smoking (\%) & 23 (20 to 25$)$ & 41 (31 to 50$)$ & $27(23$ to 30$)$ & 18 (15 to 21$)$ & $14(9$ to 19$)$ & $<0.001$ \\
\hline Angina pectoris at rest $>48 \mathrm{~h}(\%)$ & $16(14$ to 18$)$ & 11 (5 to 17) & $14(11$ to 17$)$ & $19(16$ to 22$)$ & 17 (11 to 23$)$ & 0.073 \\
\hline Angina pectoris at rest $<48 \mathrm{~h}(\%)$ & 69 (67 to 72$)$ & $67(58$ to 76$)$ & $70(66$ to 74$)$ & 68 (64 to 72$)$ & 72 (65 to 78$)$ & 0.714 \\
\hline Non- $Q$ wave $M I(\%)$ & 15 (13 to 17$)$ & $22(14$ to 30$)$ & $16(13$ to 19$)$ & $13(10$ to 16$)$ & $11(7$ to 16$)$ & 0.060 \\
\hline Mechanical CPR (\%) & $1.4(0.8$ to 2.0$)$ & $0.9(0$ to 2.8$)$ & $0.7(0$ to 1.4$)$ & $1.2(0.3$ to 2.1$)$ & $4.0(1.1$ to 6.9$)$ & 0.013 \\
\hline Defibrillation (only) (\%) & $1.7(1.0$ to 2.4$)$ & $1.9(0$ to 4.5$)$ & $1.3(0.3$ to 2.2$)$ & $1.2(0.3$ to 2.1$)$ & 4.6 (1.4 to 7.7$)$ & 0.020 \\
\hline Cardiogenic shock (\%) & $0.9(0.4$ to 1.4$)$ & 0 & $0.6(0$ to 1.2$)$ & $1.2(0.3$ to 2.1$)$ & $1.7(0$ to 3.6$)$ & 0.313 \\
\hline New ST depression $\geqslant 1 \mathrm{~mm}(\%)$ & $10(8$ to 11$)$ & $4(1$ to 7$)$ & $9(7$ to 12$)$ & $9(7$ to 11$)$ & $15(9$ to 20$)$ & 0.021 \\
\hline New $T$ wave inversion $\geqslant 1 \mathrm{~mm}(\%)$ & $29(26$ to 31$)$ & $38(28$ to 47$)$ & $31(27$ to 35$)$ & $25(22$ to 29$)$ & $27(21$ to 34$)$ & 0.029 \\
\hline Troponin $\mathrm{T} \geqslant 0.01 \mu \mathrm{g} / \mathrm{l}(\%)$ & $56(53$ to 59$)$ & $52(42$ to 62$)$ & $55(50$ to 60$)$ & $53(48$ to 58$)$ & $72(64$ to 80$)$ & 0.002 \\
\hline White cell count $\left(\times 10^{9} / \mathrm{I}\right)$ & $8.9(7.4)$ & $9.1(2.7)$ & $8.7(3.0)$ & $8.5(3.7)$ & $10.6(18.9)$ & 0.010 \\
\hline Platelet count $\left(\times 10^{9} / \mathrm{I}\right)$ & $235(75)$ & $232(62)$ & $235(66)$ & $234(79)$ & $241(92)$ & 0.661 \\
\hline Coronary vessels with $\geqslant 50 \%$ stenosis $(\%)$ & & & & & & 0.001 \\
\hline 0 & $13(12$ to 15$)$ & $18(10$ to 25$)$ & $15(12$ to 18$)$ & 12 (9 to 15$)$ & $10(5$ to 15$)$ & \\
\hline 1 & 25 (23 to 27$)$ & $31(22$ to 40$)$ & $29(25$ to 33$)$ & $22(18$ to 25$)$ & $18(12$ to 24$)$ & \\
\hline 2 & 23 (21 to 25$)$ & 23 (14 to 31$)$ & 23 (19 to 27$)$ & 24 (20 to 28$)$ & 18 (12 to 24$)$ & \\
\hline 3 & 39 (36 to 41$)$ & 29 (20 to 38$)$ & 33 (29 to 37 ) & $42(38$ to 46$)$ & $53(45$ to 61$)$ & \\
\hline Percutaneous coronary intervention (\%) & 56 (53 to 58$)$ & 58 (48 to 67$)$ & 58 (54 to 62$)$ & $55(51$ to 59$)$ & 51 (43 to 58 ) & 0.372 \\
\hline With stent (\%) & 80 (77 to 83$)$ & 83 (73 to 93$)$ & 78 (73 to 83$)$ & $80(76$ to 85$)$ & 80 (71 to 89$)$ & 0.810 \\
\hline With Gp Ilb/Illa antagonists (\%) & $12(9$ to 14$)$ & $9(1$ to 16$)$ & 11 (7 to 14$)$ & 11 (7 to 15$)$ & $21(12$ to 30$)$ & 0.060 \\
\hline Coronary artery bypass grafting (\%) & $14(12$ to 16$)$ & $9(4$ to 15$)$ & $12(10$ to 15$)$ & 15 (12 to 18$)$ & 21 (15 to 27$)$ & 0.016 \\
\hline Medical treatment (\%) & $30(28$ to 32$)$ & 33 (24 to 42$)$ & 30 (26 to 34$)$ & 30 (26 to 34$)$ & 28 (22 to 35$)$ & 0.877 \\
\hline
\end{tabular}

and $5.1 \%$ with GFR $<60 \mathrm{ml} / \mathrm{min} / 1.73 \mathrm{~m}^{2}$ (hazard ratio (HR) 4.0 , $95 \%$ CI 1.8 to $9.1 ; \mathrm{p}=0.001)$. The incidence of inhospital non-fatal myocardial infarction was low and not different between the GFR ranges.

During total follow up, mortality was significantly higher among patients with a GFR $<60 \mathrm{ml} / \mathrm{min} / 1.73 \mathrm{~m}^{2}$ of body surface area than among patients with higher GFR (table 2 ). Relative to patients in the higher GFR ranges, patients with GFR $<60 \mathrm{ml} / \mathrm{min} / 1.73 \mathrm{~m}^{2}$ were four times more likely to die during follow up (HR 4.0; $\mathrm{p}<0.001$ ). The incidence of nonfatal myocardial infarction during total follow up was not different between the GFR ranges. Kaplan-Meier survival analysis showed cumulative three year survival rates of $92.6 \%$ with GFR $\geqslant 130 \mathrm{ml} / \mathrm{min} / 1.73 \mathrm{~m}^{2}$, 95.5\% with GFR 90$129 \mathrm{ml} / \mathrm{min} / 1.73 \mathrm{~m}^{2}, \quad 91.9 \%$ with GFR $60-89 \mathrm{ml} / \mathrm{min} /$ $1.73 \mathrm{~m}^{2}$, and $76.8 \%$ with GFR $<60 \mathrm{ml} / \mathrm{min} / 1.73 \mathrm{~m}^{2}$ ( $p<0001$ by log rank) (fig 1 ). The cumulative three year survival rate was $96.9 \%$ among patients with creatinine concentrations on admission not available.

\section{Subgroup analysis}

The predictive value of GFR was irrespective of the presence or absence of diabetes (fig 2). The cumulative three year survival rates among non-diabetic and diabetic patients with GFR $<60 \mathrm{ml} / \mathrm{min} / 1.73 \mathrm{~m}^{2}$ were $78.9 \%$ and $74.7 \%$, respectively (HR for diabetes $2.0,95 \%$ CI 0.9 to $4.4 ; \mathrm{p}=0.09$ ). Non-diabetic patients with GFR $<60 \mathrm{ml} / \mathrm{min} / 1.73 \mathrm{~m}^{2}$ were at higher risk of death than were diabetic patients with GFR $>60 \mathrm{ml} / \mathrm{min} / 1.73 \mathrm{~m}^{2}$ (HR 1.9, 95\% CI 1.0 to 3.8; $\mathrm{p}=0.058$ ).

Renal function was predictive of long term mortality irrespective of the revascularisation method applied. Patients with a GFR $<60 \mathrm{ml} / \mathrm{min} / 1.73 \mathrm{~m}^{2}$ of body surface area had an HR of 3.6 (95\% CI 1.7 to $7.6 ; p=0.001$ ) if receiving PCI and an HR of 3.9 (95\% CI 1.9 to 8.1 ; p $<0.001$ ) if receiving CABG. HR was 2.9 (95\% CI 0.9 to $8.8 ; p=0.065)$ for those being managed without revascularisation and with medical treatment only. Among patients without a $\geqslant 50 \%$ stenosis in the epicardial segments of the coronary vessels $(n=173)$ and therefore presumably with either

Table 2 Association between glomerular filtration rate on admission and outcome

\begin{tabular}{|c|c|c|c|c|c|c|}
\hline & \multicolumn{4}{|c|}{ Group by GFR $\left(\mathrm{ml} / \mathrm{min} / 1.73 \mathrm{~m}^{2}\right)$} & \multirow{2}{*}{$\begin{array}{l}\text { Hazard ratio } \\
(95 \% \mathrm{Cl})^{*}\end{array}$} & \multirow[b]{2}{*}{ p Value* } \\
\hline & $\geqslant 130(n=106)$ & $90-129(n=548)$ & $60-89(n=570)$ & $<60(n=176)$ & & \\
\hline \multicolumn{7}{|l|}{ In-hospital (\%) } \\
\hline Death & 0 & $0.4(0$ to 0.9$)$ & 2.6 (1.3 to 4.0$)$ & 5.1 (1.8 to 8.4$)$ & $4.0(1.8$ to 9.1$)$ & 0.001 \\
\hline Non-fatal MI & 0 & $2.7(1.4$ to 4.1$)$ & 3.3 (1.9 to 4.8$)$ & $2.3(0.1$ to 4.5$)$ & $1.0(0.4$ to 2.9$)$ & 0.984 \\
\hline \multicolumn{7}{|l|}{ Total follow up (\%) } \\
\hline Death & $3.8(0.1$ to 7.5$)$ & 2.6 (1.2 to 3.9$)$ & 6.5 (4.5 to 8.5$)$ & 15.4 (10.0 to 20.8$)$ & $4.0(2.5$ to 6.4$)$ & $<0.001$ \\
\hline Non-fatal MI & $6.6(1.8$ to 11.4$)$ & $3.1(1.7$ to 4.6$)$ & 5.1 (3.3 to 6.9$)$ & $3.4(0.7$ to 6.2$)$ & $1.0(0.4$ to 2.3$)$ & 0.983 \\
\hline $\begin{array}{l}\text { Combined end point of death or } \\
\text { non-fatal Ml }\end{array}$ & 10.4 (4.5 to 16.3 ) & 5.5 (3.6 to 7.4$)$ & 11.2 (8.6 to 13.8 ) & 17.7 (12.0 to 23.4$)$ & 2.5 (1.7 to 3.7$)$ & $<0.001$ \\
\hline
\end{tabular}




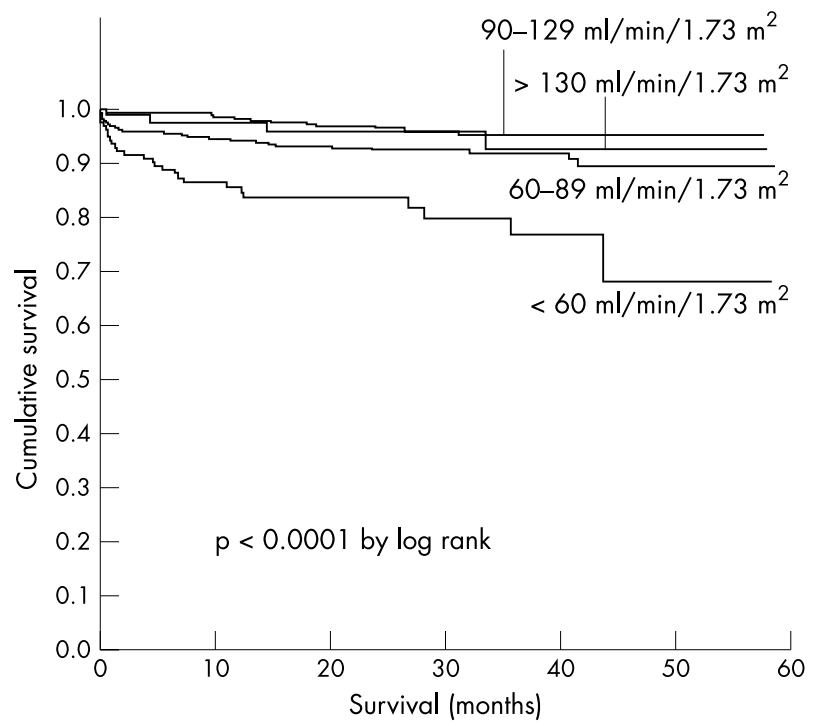

\begin{tabular}{|c|c|c|c|c|c|c|c|}
\hline \multirow[t]{4}{*}{ Number at risk: } & 106 & 67 & 51 & 31 & 17 & 7 & $>130 \mathrm{ml} / \mathrm{min} / 1.73 \mathrm{~m}^{2}$ \\
\hline & 548 & 370 & 253 & 157 & 82 & 28 & $90-129 \mathrm{ml} / \mathrm{min} / 1.73 \mathrm{~m}^{2}$ \\
\hline & 570 & 384 & 247 & 147 & 89 & 22 & $60-89 \mathrm{ml} / \mathrm{min} / 1.73 \mathrm{~m}^{2}$ \\
\hline & 176 & 94 & 64 & 36 & 15 & 6 & $<60 \mathrm{ml} / \mathrm{min} / 1.73 \mathrm{~m}^{2}$ \\
\hline
\end{tabular}

thromboembolic, vasospastic, microvascular, or non-cardiac disease, the event rate during follow up was very low. Only four patients died or experienced non-fatal myocardial infarction. Therefore, this study did not have sufficient statistical power to assess the predictive value of renal function in this subset of patients.

\section{Multivariate analysis}

Together with calculated GFR, all baseline, demographic, clinical, and angiographic variables shown in table 1 were entered into a multivariate Cox regression analysis. After adjustment for these cofounders, a GFR $<60 \mathrm{ml} / \mathrm{min} /$ $1.73 \mathrm{~m}^{2}$ of body surface area was found to be a strong independent predictor of long term mortality (HR 2.6;

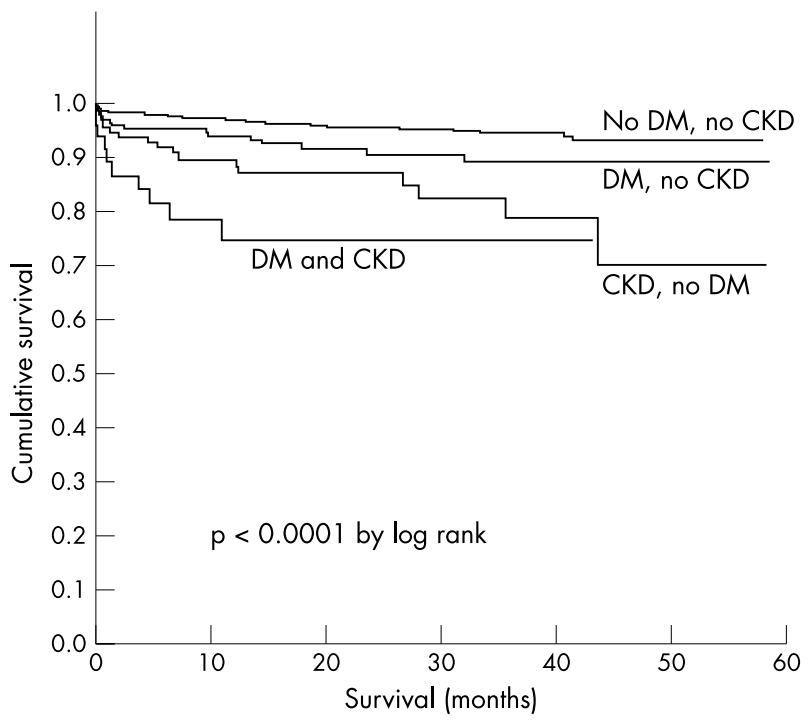

Figure 2 Cumulative survival in relation to the presence of diabetes mellitus (DM) and chronic kidney disease (CKD). CKD was defined as a glomerular filtration rate $<60 \mathrm{ml} / \mathrm{min} / 1.73 \mathrm{~m}^{2} .8$
Figure 1 Cumulative survival in relation to glomerular filtration rate on admission. $p=0.001)$ (table 3 ). Of note, diabetes fell out of the predictive model when renal function was considered.

\section{DISCUSSION}

This large study of 1400 consecutive patients with UA/ NSTEMI treated uniformly very early and predominantly with PCI confirmed baseline renal function as a strong independent predictor of in-hospital and long term mortality and thereby extends this important finding to this latest revascularisation strategy. With its universal availability, calculated GFR may serve as an inexpensive new tool for risk stratification in UA/NSTEMI. The increased risk of death with chronic kidney disease was independent of and additive to the risk associated with diabetes, in full agreement with an observation in CABG patients reported by the BARI (bypass angioplasty revascularisation investigation) investigators. ${ }^{17}$ Moreover, when diabetes and renal function were taken into consideration together, chronic kidney disease was the dominant risk factor. The adjusted HR for long term mortality was 2.6 for those with a GFR of $<60 \mathrm{ml} / \mathrm{min} /$ $1.73 \mathrm{~m}^{2}$, whereas diabetes was no longer an independent predictor.

Table 3 Independent predictors of long term mortality in multivariate analysis

\begin{tabular}{lll}
\hline & HR (95\% Cl) & p Value \\
\hline GFR $<60 \mathrm{ml} / \mathrm{min} / 1.73 \mathrm{~m}^{2}$ & $2.55(1.46$ to 4.46$)$ & 0.001 \\
Cardiogenic shock & $5.05(1.77$ to 14.45$)$ & 0.003 \\
White cell count $>10 \times 10^{9} / \mathrm{I}$ & $3.10(1.82$ to 5.28$)$ & $<0.001$ \\
Troponin $\mathrm{T} \geqslant 0.01 \mu \mathrm{g} / \mathrm{I}$ & $2.46(1.25$ to 4.84$)$ & 0.010 \\
Coronaries with $\geqslant 50 \%$ stenosis & $1.59(1.12$ to 2.26$)$ & 0.010 \\
Age (continuous) & $1.07(1.04$ to 1.10$)$ & $<0.001$ \\
T wave inversion & $0.44(0.21$ to 0.92$)$ & 0.030 \\
\hline
\end{tabular}

For the comparison of GFR $<60 \mathrm{ml} / \mathrm{min}$ versus $\geqslant 60 \mathrm{ml} / \mathrm{min}$ cardiogenic shock versus no cardiogenic shock, white cell count $>10 \times 10^{9} / \mathrm{l}$ versus white cell count $\leqslant 10 \times 10^{9} / \mathrm{l}$, troponin $\mathrm{T} \geqslant 0.01 \mu \mathrm{g} / \mathrm{l}$ versus troponin $\mathrm{T}<0.01 \mu \mathrm{g} / \mathrm{l}$, for one additional coronary artery with $\geqslant 50 \%$ stenosis, for an increase in age of one year, and T wave inversion versus no $T$ wave inversion.

$\mathrm{Cl}$, confidence interval; $\mathrm{HR}$, hazard ratio. 
Among the explanations for why chronic kidney disease is such a potent risk factor for adverse outcomes in UA/ NSTEMI, excess co-morbidity, less use of beneficial treatments for patients with chronic kidney disease, excess toxicity from conventional treatments used, and the unique pathobiology of the chronic kidney disease state seem to be the most decisive. ${ }^{8}$ Given the importance of the under use of cardioprotective treatments for patients with chronic kidney disease and the finding that low utilisation of reperfusion strategies contributed significantly to the poor prognosis of these patients in previous studies, ${ }^{10}$ this study appears particularly strong in that it is based on a prospective, consecutive, and unselected patient cohort and that a uniform revascularisation strategy was applied to all patients. These factors eliminate selection bias and ease the extrapolation of findings into clinical practice. Therefore, our data support the findings of the TACTICSTIMI 18 (treat angina with Aggrastat and determine cost of therapy with an invasive or conservative strategythrombolysis in myocardial infarction 18) trial, where patients with a serum creatinine concentration of more than $2.5 \mathrm{mg} / \mathrm{dl}(221 \mu \mathrm{mol} / \mathrm{l})$, a history of PCI or CABG within the preceding six months, factors associated with an increased risk of bleeding, cardiogenic shock, or severe systemic disorders were excluded. ${ }^{18}$ Moreover, the median time interval from admission to PCI was five hours in this study as compared with 25 hours in the invasive strategy of the TACTICS-TIMI 18 trial. $^{18}$ Other particular features of the present study are the long term follow up and that the extent of coronary artery disease was quantified for all patients and entered into the multivariate analysis as a potential confounder.

Rationale for renal function as a predictor of outcome Our results extend renal function as a powerful prognostic factor to an increasingly common disease treated with the latest revascularisation strategy. Very early revascularisation with predominantly PCI does not ameliorate the negative prognostic impact of renal function. The excess risk in patients with chronic kidney disease observed in previous studies can therefore not be sufficiently explained by lower efficacy and greater adverse events associated with thrombolytic treatment or extended periods of conservative antithrombotic and anti-ischaemic treatment. Our data support the importance of excess co-morbidities ${ }^{8}$ contributing to the inferior outcome for patients with impaired renal function. Firstly, patients with a GFR $<60 \mathrm{ml} / \mathrm{min} / 1.73 \mathrm{~m}^{2}$ were older, they were more often diabetic, and coronary artery disease was more advanced with high rates of prior myocardial infarction and three vessel disease. Secondly, UA/NSTEMI was more severe in patients with a GFR $<60 \mathrm{ml} / \mathrm{min} /$ $1.73 \mathrm{~m}^{2}$, as cardiopulmonary resuscitation, defibrillation, ST segment depression, and increased troponin $\mathrm{T}$ were seen more often than among patients in the higher GFR ranges. However, even after adjustment for these differences, the presence of a GFR $<60 \mathrm{ml} / \mathrm{min} / 1.73 \mathrm{~m}^{2}$ was still predictive of long term mortality. Therefore, the unique pathobiology of the chronic kidney disease state $^{8}$ seemed to contribute additionally to mortality during follow up.

This study was not designed to clarify the causal mediators of renal risk. Candidate mechanisms may include the presence of left ventricular hypertrophy, diastolic left ventricular dysfunction, ${ }^{71}$ pharmacological interactions, endothelial dysfunction, ${ }^{7}$ more aggressive atherosclerosis related to increases in serum homocysteine, ${ }^{20}$ increased sympathetic nerve activity, ${ }^{21}$ activated inflammatory and procoagulant pathways, ${ }^{22}$ and angiography related complications such as contrast nephropathy. ${ }^{23}{ }^{24}$
Renal function in patients undergoing elective $\mathrm{PCI}$

Recent studies have extended the correlation between renal insufficiency and clinical outcome to patients undergoing elective PCI. ${ }^{25-27}$ Chronic kidney disease was independently associated with mortality and other adverse events during and after PCI, in a dose dependent manner. Risk increased even when renal insufficiency was mild, with a doubling of mortality at one year. ${ }^{25}$

\section{Unique risks and benefits of revascularisation among patients with chronic kidney disease}

Coronary angiography, PCI, and CABG are associated with increased morbidity and mortality among patients with chronic kidney disease. ${ }^{7}{ }^{1725-29}$ This excess in risk is at least partly explained by the patients' baseline characteristics. However, patients with chronic kidney disease are a high risk subgroup of patients with UA/NSTEMI and that is exactly the subset of patients who derive the maximum benefit from early revascularisation. ${ }^{2-6}$ Randomised trials specifically including patients with chronic kidney disease are lacking but would be highly desirable. The cumulative three year survival rate was $76.8 \%$ among patients with GFR $<60 \mathrm{ml} /$ $\mathrm{min} / 1.73 \mathrm{~m}^{2}$ in this study. This compares favourably with cohorts treated primarily medically. ${ }^{9-11}$ Although any comparison with historical controls has important limitations, our data along with those of others suggest that patients with chronic kidney disease fair better with early revascularisation. ${ }^{235618}$ This is further supported by recent registry data suggesting that coronary stenting, which was used in our study as the predominant revascularisation procedure, has significantly improved procedural success rates and long term outcome for patients with chronic kidney disease. ${ }^{29}$

\section{Limitations}

Firstly, serum creatinine was used for the calculation of GFR. This measure has limitations, as it may not be in a stable state and may reflect hydration status. Secondly, any equation for the calculation of GFR inherently includes age, and age has been a consistent factor in predicting cardiac outcome.

\section{Conclusion}

Renal function is a strong independent predictor of inhospital and long term mortality in UA/NSTEMI treated with very early revascularisation. With its universal availability, GFR may serve as an inexpensive new tool for risk stratification in UA/NSTEMI.

\section{ACKNOWLEDGEMENTS}

This study was supported by research grants from the Novartis Foundation, the Krokus Foundation, and the University of Basel (to Dr Mueller).

\section{Authors' affiliations}

C Mueller*, F-J Neumann, H J Buettner, Herz-Zentrum, Bad Krozingen, Germany

André P Perruchoud, University Hospital Basel, Department of Internal Medicine, Basel, Switzerland

*Also at the University Hospital Basel

\section{REFERENCES}

1 Clancy M. Chest pain units: evidence of their usefulness is limited but encouraging. BMJ 2002;325:116-7.

2 Braunwald E, Antman EM, Beasley JW, et al. ACC/AHA 2002 guideline update for the management of patients with unstable angina and non-STsegment elevation acute myocardial infarction: a report of the American College of Cardiology/American Heart Association task force on practice guidelines (committee on the management of patients with unstable angina) American College of Cardiology/American Heart Association, 2002. 
www.acc.org/clinical/guidelines/unstable/unstable.pdf (accessed January 2003)

3 Neumann FJ, Kastrati A, Pogatsa-Murray G, et al. Evaluation of prolonged antithrombotic pretreatment ("cooling-off strategy") before intervention in patients with unstable coronary syndromes: a randomized controlled trial. JAMA 2003;290:1593-9.

4 Cannon CP, Weintraub WS, Demopoulos LA, et al. Comparison of early invasive and conservative strategies in patients with unstable coronary syndromes treated with the glycoprotein Ilb/Illa inhibitor tirofiban. NEngl J Med 2001;344:1879-87.

5 Spacek R, Widimsky P, Straka Z, et al. Value of first day angiography/ angioplasty in evolving non-ST segment elevation myocardial infarction: an open multicenter randomized trial: the VINO study. Eur Heart J

2002;23:230-8.

6 European Society of Cardiology. The task force on the management of acute coronary syndromes of the European Society of Cardiology. Management of acute coronary syndromes in patients presenting without ST-segment elevation. Eur Heart J 2002;23:1809-40.

7 Ruilope LM, van Veldhuisen DJ, Ritz E, et al. Renal function: the Cinderella of cardiovascular risk profile. J Am Coll Cardiol 2001;38:1782-7.

8 McCullough PA. Why is chronic kidney disease the spoiler for cardiovascular outcomes? J Am Coll Cardiol 2003;41:725-8.

9 Beattie JN, Soman SS, Sandberg KR, et al. Determinants of mortality after myocardial infarction in patients with advanced renal dysfunction. Am J Kidney Dis 2001;37:1191-200.

10 Herzog CA, Ma JZ, Collins AJ. Poor long-term survival after acute myocardial infarction among patients on long-term dialysis. N Engl J Med 1998;339:799-805.

11 Sorensen CR, Brendorp B, Rask-Madsen C, et al. The prognostic importance of creatinine clearance affer myocardial infarction. Eur Heart $J$ 2002;23:948-52.

12 McCullough PA, Soman SS, Shah SS, et al. Risks associated with renal dysfunction in patients in the coronary care unit. J Am Coll Cardiol 2000;36:679-84

13 Braunwald E. Unstable angina: a classification. Circulation 1989;80:410-4.

14 Levey AS. Nondiabetic kidney disease. N Engl J Med 2002;347:1505-11.

15 Levey AS, Bosch JP, Lewis JB, et al. A more accurate method to estimate glomerular filtration rate from serum creatinine: a new prediction equation. Ann Intern Med 1999;130:461-70.
16 National Kidney Foundation. K/DOQI clinical practice guidelines for chronic kidney disease: evaluation, classification and stratification. Am J Kidney Dis 2002;39(2 suppl 1):S1-266.

17 Szczech LA, Best PJ, Crowley E, et al. Outcomes of patients with chronic renal insufficiency in the bypass angioplasty revascularization investigation. Circulation 2002;105:2253-8.

18 Januzzi JL, Cannon CP, DiBattiste PM, et al. Effects of renal insufficiency on early invasive management in patients with acute coronary syndromes (the TACTICS-TIMI 18 trial). Am J Cardiol 2002;90:1246-9.

19 Kaplinsky E. Significance of left ventricular hypertrophy in cardiovascular morbidity and mortality. Cardiovasc Drugs Ther 1994;8(suppl 3):549-56.

20 Boushey CJ, Beresford SA, Omenn GS, et al. A quantitative assessment of plasma homocysteine as a risk factor for vascular disease: probable benefits of increasing folic acid intakes. JAMA 1995;274:1049-57.

21 Hausberg M, Kosch M, Harmelink P, et al. Sympathetic nerve activity in endstage renal disease. Circulation 2002;106:1974-9.

22 Shlipak MG, Fried LF, Crump C, et al. Elevations of inflammatory and procoagulant biomarkers in elderly persons with renal insufficiency. Circulation 2003:107:87-92.

23 Levy EM, Viscoli CM, Horwitz RI. The effect of acute renal failure on mortality. A cohort analysis. JAMA 1996;275:1489-94.

24 McCullough PA, Wolyn R, Rocher LL, et al. Acute renal failure after coronary intervention: incidence, risk factors, and relationship to mortality. Am J Med 1997: 103:368-75.

25 Best PJM, Lennon R, Ting HH, et al. The impact of renal insufficiency on clinical outcomes in patients undergoing percutaneous coronary interventions. J Am Coll Cardiol 2002;39:1113-9.

26 Gruberg L, Dangas G, Mehran R, et al. Clinical outcome following percutaneous coronary interventions in patients with chronic renal failure. Cathet Cardiovasc Interv 2002;55:66-72.

27 Gruberg L, Weissman NJ, Pichard AD, et al. Impact of renal function on morbidity and mortality after percutaneous aortocoronary saphenous vein graft intervention. Am Heart J 2003;145:529-34.

28 Rubenstein MH, Harrell LC, Sheynberg BV, et al. Are patients with renal failure good candidates for percutaneous coronary revascularization in the new device era. Circulation 2000; 102:2966-72.

29 Herzog CA, Ma JZ, Collins AJ. Comparative survival of dialysis patients in the United States after coronary angioplasty, coronary stenting, and coronary artery bypass surgery and impact of diabetes. Circulation 2002;106:2207-11.

\section{IMAGES IN CARDIOLOGY}

\section{Free floating thrombus in left atrium}

A 78 year old male patient presented with dyspnoea (New York Heart Association functional class III) with past history of left sided hemiparesis two years previously with atrial fibrillation on ECG. Chest $x$ ray showed evidence of enlargement of the left atrium, right ventricle, and right atrium with redistribution of blood flow toward the lung apices.

$M$ mode echocardiography showed multiple dense lines over the mitral valve area (thickened valve), reduced E-F slope of mitral valve $(15 \mathrm{~mm} / \mathrm{s})$, with erratically moving multiple lines in an enlarged left atrium $(73 \mathrm{~mm})$.

Two dimensional echocardiography showed thickened, non-pliable leaflets, and a calcified valve annulus with a mitral valve area of approximately $0.7 \mathrm{~cm}^{2}$

A globular, hyperechoic mass (thrombus) of $3 \times 2 \mathrm{~cm}$ was detected in an enlarged left atrium. It was moving freely from the upper part of the left atrium to the lower part and was bouncing back after striking the mitral valve leaflets. The mass was unable to find its way through the mitral valve as it was larger than the mitral valve orifice. The mass was a dislodged thrombus that had failed to embolise.
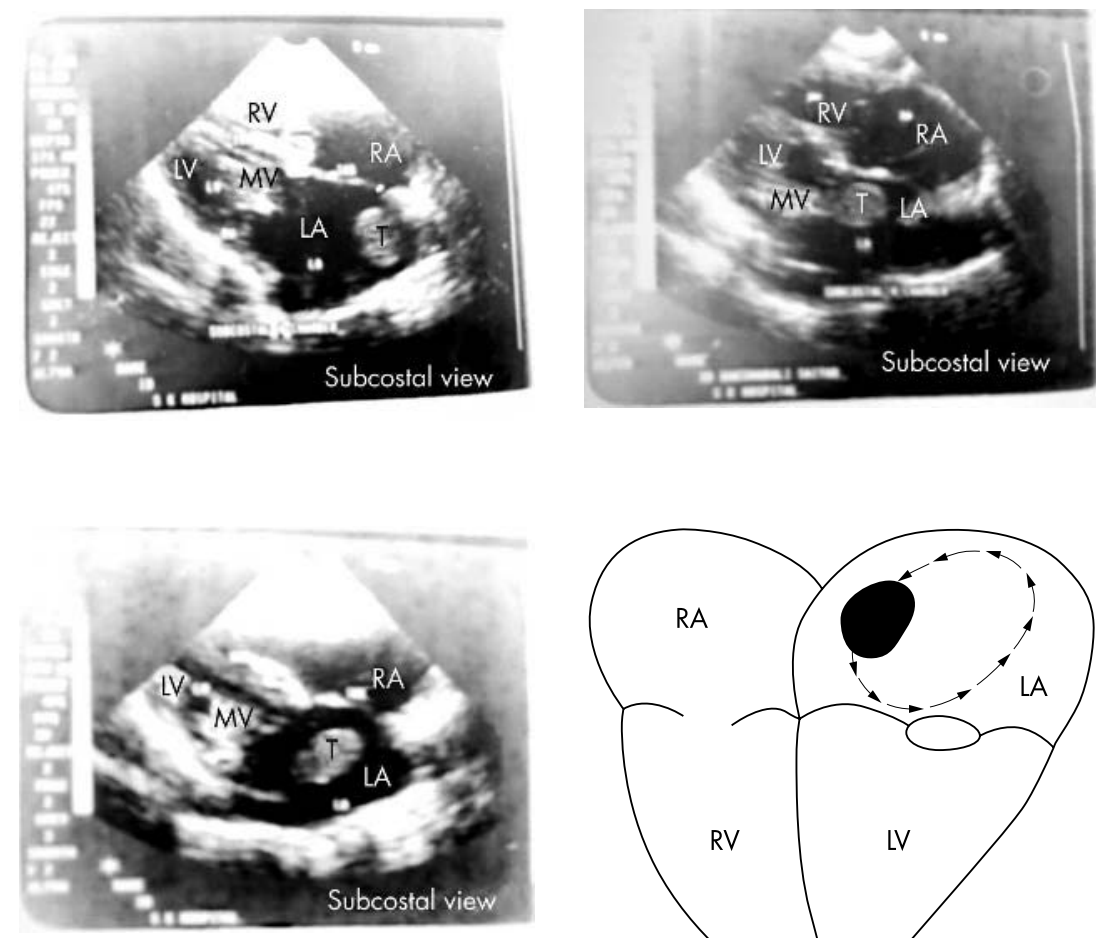

P Vaid

pradipvaid@yahoo.com 